\title{
A Taxionomia revisada de Bloom aplicada à avaliação: um estudo de provas escritas de Matemática
}

\section{The revised Bloom's Taxonomy applied to assessment: a study of Mathematics written tests}

\author{
André Luis Trevisan ${ }^{1}$. Roseli Gall do Amaral ${ }^{2}$
}

\begin{abstract}
Resumo: Este artigo apresenta uma análise, à luz da Taxionomia revisada de Bloom, de itens de provas escritas de Matemática elaboradas por professores do Ensino Fundamental II e do Ensino Médio de escolas públicas. Esses professores participaram de oficinas que discutiram a temática "avaliação e aprendizagem", projeto de extensão que ocorreu no ano de 2013, e foram convidados a analisar provas escritas que eles mesmos elaboraram. Os resultados apontaram uma prevalência de itens classificados nos níveis mais baixos do domínio cognitivo da Taxionomia (lembrar, entender e aplicar) e uma quase ausência de itens nos níveis mais elevados (analisar, avaliar e criar). Tais resultados corroboram a necessidade de estudos e propostas de formação continuada que oportunizem aos professores repensar: (i) os instrumentos avaliativos que utilizaram (em geral, prioritariamente a prova escrita), (ii) a elaboração das tarefas que propõem (em geral, restritas aos modelos presentes em livros didáticos) e (iii) a sua própria prática avaliativa.
\end{abstract}

Palavras-chave: Avaliação da aprendizagem. Prova escrita. Taxionomia de Bloom.

\begin{abstract}
This article presents an analysis based on the Revised Bloom's Taxonomy of items of Mathematics written test questions prepared by teachers of Secondary School and High School public school. These teachers participated in workshops that discussed the theme "assessment and learning", a project in 2013 and they were asked to analyze the written test that they prepared. The results showed the prevalence of items classified in the lower levels of the cognitive domain of the Taxonomy (remember, understand and apply) and a near absence of items in the most developed levels (analyze, evaluate and create). These results support the need for studies and continuing education projects that encourages the teachers rethink: (i) the assessment instruments that they use (in general, mainly the written test); (ii) the development of the tasks proposed (generally restricted to "exercises-type" present in textbooks) and (iii) its own assessment practice.
\end{abstract}

Keywords: Assessment of school learning. Written test. Bloom's Taxionomy.

\footnotetext{
${ }^{1}$ Universidade Tecnológica Federal do Paraná (UTFPR), Departamento de Matemática, Programa de Mestrado Profissional em Ensino de Matemática, Londrina, PR, Brasil. E-mail: <andrelt@utfpr.edu.br>

${ }^{2}$ Universidade Tecnológica Federal do Paraná (UTFPR), Departamento de Educação, Apucarana, PR, Brasil.
} 


\section{Introdução}

O projeto "Oficinas de avaliação: uma proposta para repensar a prática avaliativa na Educação Básica”’ é uma ação de extensão iniciada em 2013, consistindo em encontros de formação continuada com professores de escolas públicas de um município da região metropolitana de Londrina- PR. As atividades propostas incluíram o oferecimento de módulos independentes, cada um deles correspondendo a 10 encontros presenciais de uma hora e trinta minutos, realizados semanalmente, e mais 15 horas de atividades não presenciais, totalizando 30 horas de atividades, com duração de um trimestre. As atividades referentes aos momentos não presenciais consistiram na leitura de textos e desenvolvimento de investigações junto às próprias turmas com as quais esses professores atuavam. Nos momentos presenciais, os participantes foram incentivados a tecer suas impressões a respeito das leituras propostas, apresentar resultados de suas investigações, confrontar a teoria com sua própria prática avaliativa, compartilhar experiências e analisar conjuntamente provas escritas que eles mesmos elaboraram e a produção escrita de seus próprios estudantes em questões dessas provas. Em suma, as discussões realizadas objetivaram fomentar uma perspectiva de avaliação como prática de investigação e oportunidade de aprendizagem (BURIASCO; FERREIRA; CIANI, 2009).

Ao longo do ano de 2013 foram oferecidos três módulos. O primeiro deles foi destinado a professores da área de Matemática e teve oito participantes. Dentre as atividades propostas nesse módulo, destaca-se a análise de provas escritas elaboradas por esses professores e aplicadas em suas turmas.

Este artigo relata um estudo dos itens de questões presentes nessas provas, tendo por base a Taxionomia revisada de Bloom (ANDERSON; KRATHWOHL, 2001), que objetiva classificar e discutir classificações desses itens, à luz do referencial teórico em tela. O estudo está organizado do seguinte modo: inicia-se contextualizando o estudo e apresentando algumas motivações iniciais, seguido do referencial teórico que fundamenta sua realização - a avaliação e a Taxionomia de Bloom. Na sequência, apresentam-se os procedimentos metodológicos, os resultados e uma discussão a partir deles, permeada por reflexões oriundas dessa experiência.

\section{A Taxionomia de Bloom e o processo de avaliação da aprendizagem}

Em 1948, um grupo de psicólogos reuniu-se em uma convenção da Associação Americana de Psicologia (APA) em Boston, e nesse encontro manifestou-se o interesse por um quadro teórico de referência que facilitasse a comunicação entre examinadores e estimulasse a pesquisa sobre avaliação, estabelecendo uma articulação entre os envolvidos no processo de avaliar. A forma mais adequada para realizar tal tarefa foi a elaboração de um sistema de classi-

\footnotetext{
${ }^{3}$ Projeto aprovado em Edital da Diretoria de Relações Empresariais e Comunitárias da UTFPR, tendo ocorrido nos anos de 2013 e 2014. É desenvolvido em paralelo com o projeto de pesquisa "Avaliação da aprendizagem em ensino de Ciências da Natureza e Matemática”, aprovado em Edital da Fundação Araucária (Convênio 386/2012). Ambos são coordenados pelo primeiro autor deste artigo, contando com a colaboração da segunda autora.
} 
ficação de objetivos que se tornasse ponto de partida e base para o planejamento educacional. Ao assumir a liderança desse projeto, Benjamin Bloom, junto com seus colaboradores, definiu como primeiro passo a divisão do trabalho de acordo com os domínios cognitivo, afetivo e psicomotor dos objetivos educacionais.

No domínio cognitivo, os objetivos educacionais focam a aprendizagem de conhecimentos, desde a recordação e compreensão de algo estudado até a capacidade de aplicar, analisar e reorganizar a aprendizagem de um modo singular e criativo, reordenando o material ou combinando-o com ideias ou métodos anteriormente aprendidos. Já no domínio afetivo, os objetivos dão ênfase aos sentimentos, emoções, aceitação ou rejeição de algo. No domínio psicomotor, os objetivos educacionais são ligados à habilidade motora, manipulação de objetos ou ações que requerem coordenação neuromuscular. São, geralmente, relacionados à caligrafia, à arte mecânica, à educação física e a cursos técnicos (BLOOM et al., 1983, p. 3-7).

Como instrumento de apoio didático-pedagógico, a Taxionomia de Bloom tem como objetivo geral contribuir com todos aqueles que direta ou indiretamente se ocupam com problemas referentes a currículo e avaliação. Em especial, visa possibilitar, no exame desses problemas, maior precisão, uma vez que selecionar currículos e avaliar são submetidos a juízos de valor. Fundamentalmente, avaliar é emitir juízo de valor, após análises e ou sínteses efetuadas. É uma apreciação qualitativa sobre dados relevantes dos processos de ensino e aprendizagem que auxilia o professor a tomar decisões sobre o seu trabalho (MORETTO, 2010). Luckesi (2002, p. 33) também afirma que a

[...] avaliação pode ser caracterizada como uma forma de ajuizamento da qualidade do objeto avaliado, fator que implica uma tomada de posição a respeito do mesmo, para aceitá-lo ou para transformá-lo. A avaliação é um julgamento de valor sobre manifestações relevantes da realidade, tenso em vista uma tomada de decisão.

Nesta perspectiva, Luckesi (2005) aponta que nas trajetórias de pesquisas sobre avaliação, que iniciaram pelo conhecimento técnico dos instrumentos de medição de aproveitamento, o educador avançou para o aprofundamento das questões teóricas, chegando à seguinte definição de avaliação escolar: um juízo de qualidade sobre dados relevantes para uma tomada de decisão. Nessa concepção, não há avaliação se ela não trouxer um diagnóstico que contribua para melhorar a aprendizagem. É nesse sentido que a Taxionomia de Bloom pode contribuir para o estabelecimento de critérios que facilitem a objetividade e rompam com a subjetividade do processo avaliativo.

A questão que norteou o presente trabalho de pesquisa foi uma análise de como o conhecimento e a aplicação da Taxionomia de Bloom poderia colaborar na elaboração de provas como instrumentos que aproximam a avaliação de uma prática de investigação e oportunidade de aprendizagem, que orientasse a construção de objetivos a serem alcançados de forma sucessiva. A taxonomia original de Bloom define seis principais categorias do domínio cognitivo: conhecimento, compreensão, aplicação, análise, síntese e avaliação. As categorias são ordenadas da mais simples para a mais complexa e, possuem uma hierarquia cumulativa, sendo a categoria mais simples pré-requisito para a próxima. São associadas ações (verbos) que auxiliam na classificação das questões da avaliação em um dos níveis da taxonomia. 
Em 1990, a taxionomia passou por um processo de revisão e, em 2001, foi publicada por Lorin Anderson e seus colaboradores. Na Taxionomia revisada de Bloom foram combinados o tipo de conhecimento a ser adquirido e o processo utilizado para a aquisição desse conhecimento (ANDERSON; KRATHWOHL, 2001). O tipo de conhecimento passou a ser designado por substantivos e os processos para atingi-los passaram a ser descritos por verbos. O nível do conhecimento, compreensão e síntese foram renomeados para relembrar, entender e criar, respectivamente, como se pode observar na Figura 1.

Conforme descrição apresentada nos Quadros 1 e 2, foram combinados o tipo de conhecimento a ser adquirido (Dimensão do conhecimento) e o processo utilizado para a aquisição desse conhecimento (Dimensão do processo cognitivo). Essas mudanças permitiram um enfoque bidimensional, tornando mais fácil a tarefa de definir com clareza os objetivos de aprendizagem e alinhá-los com as atividades de avaliação (Quadro 3).

O conhecimento e a utilização da taxionomia podem facilitar a tarefa do professor de planejar e sistematizar a avaliação. Utilizada como um suporte metodológico, que exige competência, discernimento e equilíbrio (ANTUNES, 2012, p. 10), o emprego de sua técnica permite um planejamento mais concreto e eficaz, na tentativa de tornar o ato de avaliar um componente a serviço dos processos de ensino e de aprendizagem.

Figura 1. A Taxionomia revisada de Bloom

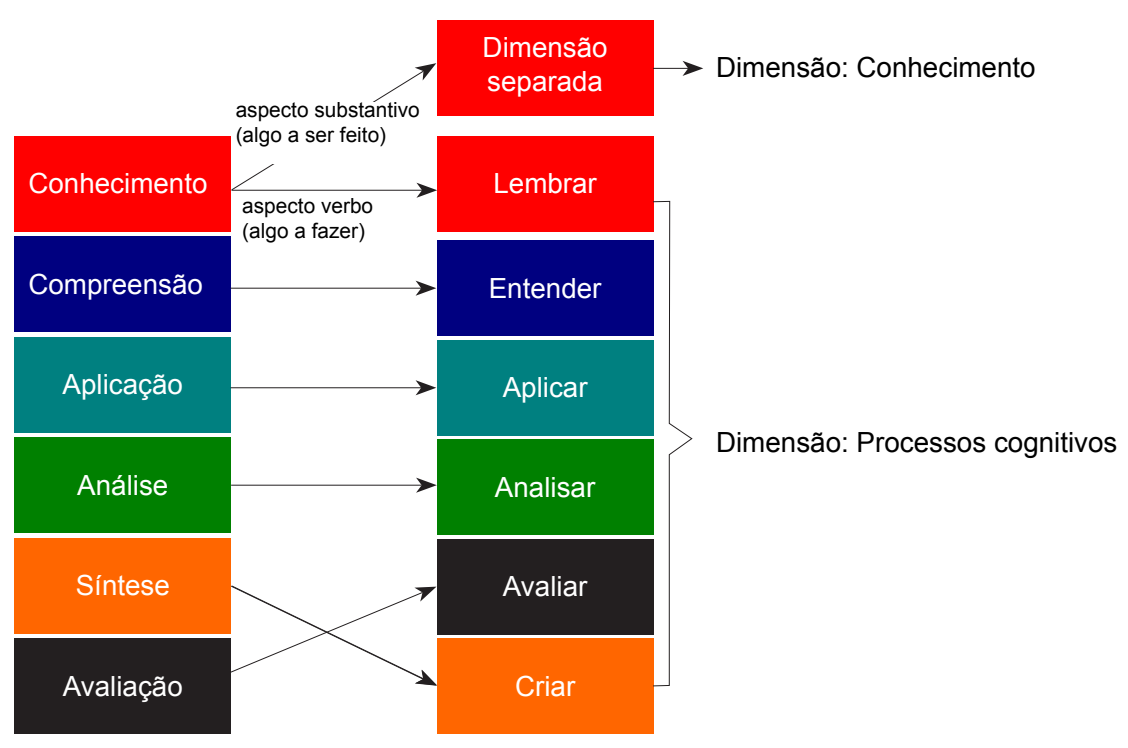

Fonte: Disponível em: <http://www.utfpr.edu.br/apucarana/estrutura-universitaria/diretorias/dirgrad/ deped-departamento-de-educacao/ii-ciclo-de-estudos-pedagogicos-material-do-primeiro-encontro $>$. Acesso em: 13 out. 2014. 
Quadro 1. Dimensão do processo cognitivo na Taxionomia revisada de Bloom

1. Lembrar: Relacionado a reconhecer e reproduzir ideias e conteúdos. Reconhecer requer distinguir e selecionar uma determinada informação e reproduzir ou recordar está mais relacionado à busca por uma informação relevante memorizada.

2. Entender: Relacionado a estabelecer uma conexão entre o novo e o conhecimento previamente adquirido. A informação é entendida quando o aprendiz consegue reproduzi-la com suas "próprias palavras".

3. Aplicar: Relacionado a executar ou usar um procedimento numa situação específica e pode também abordar a aplicação de um conhecimento numa situação nova.

4. Analisar: Relacionado a dividir a informação em partes relevantes e irrelevantes, importantes e menos importantes e entender a inter-relação existente entre as partes.

5. Avaliar: Relacionado a realizar julgamentos baseados em critérios e padrões qualitativos e quantitativos ou de eficiência e eficácia.

6. Criar: Significa colocar elementos junto com o objetivo de criar uma nova visão, uma nova solução, estrutura ou modelo utilizando conhecimentos e habilidades previamente adquiridos. Envolve o desenvolvimento de ideias novas e originais, produtos e métodos por meio da percepção da interdisciplinaridade e da interdependência de conceitos.

Fonte: Ferraz e Belhot (2010, p. 429).

Quadro 2. Dimensão do conhecimento na Taxionomia revisada de Bloom

1. Conhecimento Efetivo/Factual: relacionado ao conteúdo básico que o discente deve dominar a fim de que consiga realizar e resolver problemas apoiados nesse conhecimento. Relacionado aos fatos que não precisam ser entendidos ou combinados, apenas reproduzidos como apresentados.

2. Conhecimento Conceitual: relacionado à inter-relação dos elementos básicos num contexto mais elaborado que os discentes seriam capazes de descobrir. Elementos mais simples foram abordados e agora precisam ser conectados. Esquemas, estruturas e modelos foram organizados e explicados. Nessa fase, não é a aplicação de um modelo que é importante, mas a consciência de sua existência.

3. Conhecimento Procedimental/Procedural: relacionado ao conhecimento de "como realizar alguma coisa" utilizando métodos, critérios, algoritmos e técnicas. Nesse momento, o conhecimento abstrato começa a ser estimulado, mas dentro de um contexto único e não interdisciplinar.

4. Conhecimento Metacognitivo: relacionado ao reconhecimento da cognição em geral e da consciência da amplitude e profundidade de conhecimento adquirido de um determinado conteúdo. Em contraste com o conhecimento procedural, esse conhecimento é relacionado à interdisciplinaridade. A ideia principal é utilizar conhecimentos previamente assimilados (interdisciplinares) para resolução de problemas e/ou a escolha do melhor método, teoria ou estrutura.

Fonte: Ferraz e Belhot (2010, p. 429). 
Trevisan, A. L.; Amaral, R. G.

Quadro 3. Caráter bidimensional na Taxionomia revisada de Bloom

\begin{tabular}{|l|l|l|l|l|}
\hline \multicolumn{1}{|c|}{$\begin{array}{c}\text { Dimensão } \\
\text { do processo cognitivo }\end{array}$} & \multicolumn{3}{c|}{ Dimensão do conhecimento } \\
\cline { 2 - 5 } Lembrar & Efetivo/factual & Conceitual & Procedimental & Metacognitivo \\
\hline Entender & & & & \\
\hline Aplicar & & & & \\
\hline Analisar & & & & \\
\hline Avaliar & & & & \\
\hline Criar & & & & \\
\hline
\end{tabular}

Fonte: Ferraz e Belhot (2010, p. 430).

\section{Procedimentos metodológicos}

Neste estudo optou-se por uma investigação qualitativa de cunho interpretativo (BOGDAN; BIKLEN, 1994). A pesquisa não intenciona uma generalização dos resultados, mas uma reflexão dos mesmos, tomando por base o quadro teórico descrito.

Compuseram esse estudo os itens de provas escritas de Matemática, contemplando conteúdos do Ensino Fundamental II e do Ensino Médio. Esse material foi disponibilizado por professores de Matemática participantes do primeiro módulo do projeto de extensão, e sua utilização para fins de pesquisa foi autorizada pelos mesmos por meio da assinatura de um termo de consentimento livre e esclarecido. Embora se esteja utilizando o termo "prova", incluem-se aqui outros instrumentos de avaliação disponibilizados pelos professores, que foram utilizados para atribuição de alguma nota, e passíveis de análise da produção escrita ("atividades" de sala de aula, trabalhos, "avaliações processuais").

Esses professores apresentam percursos profissionais e pessoais diversificados, têm idades compreendidas entre os 32 e os 56 anos, apresentando experiência docente que varia entre os sete e os vinte anos de ensino, um deles graduado em Ciências com Habilitação em Matemática e os demais licenciados em Matemática, todos com formação pelo menos em nível de Pós-Graduação. À exceção de um dos professores que leciona também em uma escola particular, as provas foram aplicadas em três diferentes escolas públicas de um mesmo município onde atuam esses professores, localizado na região metropolitana do município de Londrina/PR.

O material disponibilizado incluiu 24 provas escritas, sendo três do $6^{\circ}$ ano, uma do $7^{\circ}$ ano, cinco do $8^{\circ}$ ano, sete do $9^{\circ}$ ano, duas do $1^{\circ}$ ano do Ensino Médio, e seis do $3^{\circ}$ ano do Ensino Médio, totalizando 131 itens.

Numa primeira etapa, os próprios professores foram convidados, em um dos encontros, a classificar as questões, segundo a Taxionomia (original) de Bloom (BLOOM et al., 1983), mo- 
tivados pelo estudo de um dos capítulos do livro de Moretto (2001), intitulado A prova operatória: ressignificando a Taxionomia de Bloom. A opção de utilizar esse texto como base para o trabalho com os professores deve-se a duas razões: (i) o fato de ser um texto sucinto, com linguagem clara e permeado de exemplos de questões de provas similares àquelas que usualmente estão presentes em provas escritas, e (ii) uma experiência bem-sucedida num contexto de formação continuada de professores do Ensino Superior, coordenada pelos dois primeiros autores deste artigo, na qual se fez uso deste mesmo texto (BARBOZA; TREVISAN; AMARAL, 2012).

Numa segunda etapa, ao reunirem-se para validar essas classificações, os autores deste artigo sentiram a necessidade de ajustar algumas delas e, numa busca por refiná-las, optaram por reavaliá-las, ajustando-as segundo a Taxionomia revisada de Bloom (ANDERSON et al., 2001 apud FERRAZ; BELHOT, 2010). Houve um entendimento de que essa opção não invalidaria a classificação inicial, visto que, como lembram Ferraz e Belhot (2010, p. 427), na versão revisada, "a base [original] das categorias foi mantida, continuam existindo seis categorias, o nome da taxonomia continua sendo o mesmo (eventualmente pode aparecer com a expressão 'revisada' adicionada a ele)".

\section{Resultados e discussão}

O Quadro 4 apresenta a distribuição dos itens das provas escritas analisadas, segundo a Taxionomia revisada de Bloom. Conforme apontaram Bloom et al. (1983, p. 44), ao classificar esses itens, foi necessário "conhecer ou pelo menos fazer algumas ponderações sobre as situações de aprendizagem que precederam a verificação", bem como "experimentar, realmente, resolver as questões e observar os processos mentais que utiliza”.

Quadro 4. Número dos itens das provas escritas segundo a Taxionomia revisada de Bloom

\begin{tabular}{|l|c|c|c|c|}
\hline \multirow{2}{*}{$\begin{array}{c}\text { Dimensão } \\
\text { do processo cognitivo }\end{array}$} & \multicolumn{4}{c|}{ Dimensão do conhecimento } \\
\cline { 2 - 5 } & Efetivo/factual & Conceitual & Procedimental & Metacognitivo \\
\hline Lembrar & 14 & & & \\
\hline Entender & 7 & 8 & 78 & \\
\hline Aplicar & 18 & & 3 & \\
\hline Analisar & & & & \\
\hline Avaliar & & 1 & & \\
\hline Criar & & & & \\
\hline
\end{tabular}

Fonte: Baseado em Ferraz e Belhot (2010, p. 430). 
Nesse caso, a classificação foi feita baseada no encaminhamento usual de aulas de Matemática (aula expositiva, seguida da resolução de exercícios e problemas), da sequência de conteúdos como apresentadas na maioria dos livros didáticos (conteúdo organizado de forma linear, baseado em pré-requisitos ou conhecimentos anteriores), bem como nos apontamentos feitos pelos professores durante discussões realizadas nas oficinas de formação continuada (em especial acerca de razões que os levaram a escolher determinadas questões para compor a prova). Também foi tomada como base a própria obra de Bloom et al. (1983), na qual há exemplos de questões e argumentos que justificam as classificações realizadas para cada uma delas.

Dos itens que compuseram as provas analisadas, 14 deles (correspondendo a $11 \%$ do total) referem-se à dimensão de processo cognitivo lembrar. Foram classificados nessa categoria itens cuja resolução demandava reconhecer, recordar e reproduzir informações (busca de uma informação relevante memorizada). No que diz respeito à dimensão conhecimento, todas essas se referem a um tipo de conhecimento factual (específico), relacionadas a "fatos que não precisam ser entendidos ou combinados, apenas reproduzidos como apresentados" (FERRAZ; BELHOT, 2010, p. 429).

17 itens (13\% do total) possibilitam ao estudante fazer uma interpretação própria de ideias e conteúdos apresentados pelo professor em aula, podendo ser reproduzidas com suas "próprias palavras", classificadas segundo a dimensão do processo cognitivo entender (ou compreender, segundo a terminologia utilizada na Taxionomia original). Conforme salientam Bloom et al. (1983, p. 77), deve-se atribuir ao termo aqui utilizado "um sentido mais restrito do que o usual, de vez que a compreensão não é considerada como um sinônimo de entendimento completo ou mesmo uma apreensão total da mensagem". Nesse caso, demanda-se do estudante interpretar, exemplificar, classificar, resumir, concluir, comparar ou explicar fatos, conceitos e procedimentos (correspondendo, respectivamente, às dimensões do conhecimento factual, conceitual e procedimental).

A dimensão de processo cognitivo aplicar foi a que massivamente apareceu nos itens das provas analisadas (74\% do total). Questões dessa categoria envolvem a execução ou implementação de procedimentos aprendidos numa situação específica, podendo também abordar a aplicação de um conhecimento em uma situação nova. Em sua maioria (78 das 96 questões nessa categoria) estão relacionadas à dimensão procedimental do conhecimento, relacionada ao "como realizar alguma coisa" utilizando métodos, critérios, algoritmos e técnico. Embora o conhecimento abstrato comece a ser estimulado por meio desses itens (o que os diferencia dos 18 itens referentes à dimensão factual do conhecimento - apenas reproduzir "tal qual foi apresentado"), essa aplicação restringe-se a um contexto específico, particular, não envolvendo sua extrapolação para novos contextos.

Por fim, na categoria avaliar, da dimensão processo cognitivo, foram identificadas quatro questões, envolvendo a realização de algum tipo de julgamento, podendo este ser qualitativo ou quantitativo. Tais julgamentos envolvem, no caso dos itens analisados, a mobilização de conhecimentos das dimensões conceitual (um item) e procedimental (três itens).

O Quadro 5 apresenta itens das questões da prova que exemplificam cada uma das oito células preenchidas no Quadro 4 (indicadas com a letra Q, seguidas de um dígito do 1 ao 10). No caso das células da dimensão do processo cognitivo aplicar foram apresentados mais exemplos, por ser essa a classificação que mais apareceu nos itens da prova. 
Quadro 5. Exemplo dos itens das provas escritas classificadas segundo a Taxionomia revisada de Bloom

\begin{tabular}{|c|c|c|c|c|c|}
\hline \multirow{2}{*}{$\begin{array}{c}\text { Dimensão } \\
\text { do processo } \\
\text { cognitivo }\end{array}$} & \multicolumn{5}{|c|}{ Dimensão do conhecimento } \\
\hline & \multicolumn{4}{|c|}{ Efetivo/factual } & Conceitual \\
\hline \multirow[t]{4}{*}{ Lembrar } & \multicolumn{4}{|c|}{$\begin{array}{l}\text { (Q1) Entre os diversos monômios, } \\
\text { complete o quadro: }\end{array}$} & \\
\hline & Monômio & Coeficiente & Parte Literal & Grau & \\
\hline & $0,853 a^{7} b^{8} c^{2}$ & & & & \\
\hline & \multicolumn{4}{|c|}{ (outros similares) } & \\
\hline Entender & \multicolumn{4}{|c|}{$\begin{array}{l}\text { (Q2) Agora vamos brincar de detetive. } \\
\text { As pistas são dadas, agora é só pensar } \\
\text { bem e descobrir quem sou. } \\
\text { a) Que número você formaria ao juntar } \\
5 \text { dezenas com } 10 \text { unidades? (outros } \\
\text { similares) }\end{array}$} & $\begin{array}{l}\text { (Q3) Assinale os itens que apresentam } \\
\text { grandezas proporcionais: } \\
\text { ( ) tempo de uso de um chuveiro } \\
\text { elétrico e o consumo de energia } \\
\text { correspondente. (outros similares) }\end{array}$ \\
\hline Aplicar & \multicolumn{4}{|c|}{$\begin{array}{l}\text { (Q5) Resolva as expressões abaixo } \\
\text { no verso da folha e depois registre o } \\
\text { resultado na frente de cada expressão } \\
\text { a) } 160-40+20 \text { - } 10 \text { (outros similares) } \\
\text { (Q6) Resolva as operações com } \\
\text { monômios } \\
\text { a) } 9 x^{4} g^{5} \cdot 7 x^{3} g^{9} \text { (outros similares) }\end{array}$} & \\
\hline \multicolumn{6}{|l|}{ Analisar } \\
\hline Avaliar & & & & & $\begin{array}{l}\text { (Q9) Muitos alunos colecionam } \\
\text { adesivos e por isso sempre estão } \\
\text { trocando-os com os colegas. Jéssica e } \\
\text { Ana são alunas da } 5^{\text {a }} \text { série e juntas elas } \\
\text { possuem } 29 \text { adesivos. } \\
\text { a) Quantos adesivos têm cada uma? } \\
\text { b) Podemos dizer que elas possuem } \\
\text { quantidades iguais? Por quê? }\end{array}$ \\
\hline Criar & & & & & \\
\hline
\end{tabular}


Trevisan, A. L.; Amaral, R. G.

Quadro 5. continuação

\begin{tabular}{|c|c|c|c|}
\hline \multirow{2}{*}{$\begin{array}{l}\text { Dimensão } \\
\text { do processo } \\
\text { cognitivo }\end{array}$} & \multicolumn{3}{|c|}{ Dimensão do conhecimento } \\
\hline & \multicolumn{2}{|r|}{ Procedimental } & Metacognitivo \\
\hline \multicolumn{4}{|l|}{ Lembrar } \\
\hline Entender & \multicolumn{2}{|c|}{$\begin{array}{l}\text { (Q4) Sem efetuar cálculos, escreva se as potências são positivas } \\
\text { ou negativas: } \\
\begin{array}{ll}\text { a) } y=(-3 / 4)^{3} \quad \text { (outros similares) }\end{array}\end{array}$} & \\
\hline Aplicar & \multicolumn{2}{|c|}{$\begin{array}{l}\text { (Q7) Uma aplicação de } \mathrm{R} \$ 80.000,00 \text { rendeu, em } 4 \text { meses, } \\
\mathrm{R} \$ 8.000,00 \text {. Qual é a taxa mensal de juros? } \\
\text { (Q8) Determine o valor de de modo que o triângulo } \mathrm{A}(1,0) \text {, } \\
\mathrm{B}(2,-1) \text { e } \mathrm{C}(\mathrm{a}, 2) \text { tenha área } 7 \text {. }\end{array}$} & \\
\hline \multicolumn{4}{|l|}{ Analisar } \\
\hline \multirow[t]{4}{*}{ Avaliar } & \multicolumn{2}{|c|}{$\begin{array}{l}\text { (Q10) Nilton e Márcia estão resolvendo } 2+4 \text { x } 5 \text {. } \\
\text { Veja como eles resolveram: }\end{array}$} & \\
\hline & Nilton & Márcia & \\
\hline & $\begin{array}{c}2+4 \times 5 \\
6 \times 5 \\
30\end{array}$ & $\begin{array}{c}2+4 \times 6 \\
2+20 \\
22\end{array}$ & \\
\hline & \multicolumn{2}{|c|}{$\begin{array}{l}\text { a) Quem acertou? } \\
\text { b) Justifique o que a outra pessoa fez de errado em sua } \\
\text { resolução. }\end{array}$} & \\
\hline Criar & & & \\
\hline
\end{tabular}

Fonte: Elaborado pelos autores.

A resolução de Q1 está relacionada a lembrar (verbo) terminologias específicas (substantivo): coeficiente, parte literal e grau de um monômio. Trata-se da ação mais elementar relacionada à dimensão do conhecimento, representando a linguagem básica de uma determinada área do conhecimento. Questões similares a essa e presentes nas provas analisadas envolviam, por exemplo, a classificação de equações do $2^{\circ}$ grau em completas ou incompletas, o cálculo do fatorial de números naturais (que depende exclusivamente da recordação da definição de fatorial) 
ou a associação de uma grandeza ao instrumento de medição correspondente, a partir de uma lista de possibilidades (por exemplo, grandeza tempo associada ao instrumento cronômetro).

Já para resolver Q6, é necessário lembrar (verbo) fatos específicos (para multiplicar monômios, multiplicam-se os coeficientes; para parte literal, conservam-se as bases iguais e somam os expoentes) e aplicá-los ao caso particular proposto nesse item. Outras questões classificadas deste mesmo modo envolvem a determinação de raízes de equações do $2^{\circ}$ grau (via fórmula resolutiva ou "fórmula de Bháskara”), cálculo de um número binomial, resolução de operações (“continhas") ou cálculo do valor de expressões numéricas.

Pela Taxionomia, Q6 é hierarquicamente mais complexa que Q1; porém, não se pode estabelecer uma relação direta entre ambas: o estudante pode ser capaz de mobilizar fatos específicos envolvendo a multiplicação de monômios e aplicá-los a uma situação particular, sem necessariamente lembrar a terminologia específica a eles associado. Tal situação ilustra um dos pontos ressaltados por Ferraz e Beholt (2010, p. 427): é possível aos "discentes aprenderem melhor num estágio mais elevado e depois serem capazes de entender os anteriores", flexibilidade presente na versão revisada da Taxionomia e sendo um dos pontos que a difere da versão original.

Embora tal ressalva vá ao encontro das discussões feitas há pelo menos trinta anos no campo da Educação Matemática (por meio de abordagens metodológicas como a resolução de problemas, as investigações matemáticas e a resolução de problemas), a ideia de que para adquirir uma nova habilidade pertencente ao próximo nível, o aluno deve ter dominado e adquirido a habilidade do nível anterior (o que, nesse caso, implicaria que só é capaz de resolver Q6 quem resolve Q1) parece bastante arraigada na mente e na prática dos professores ${ }^{4}$. Isso não significa que questões como Q1 não devam estar presentes em provas de Matemática, mas sim que essas não sejam objeto central e nem mesmo uma "camisa de força" no sentido do estudante ser "punido" por não lembrar terminologias às vezes inúteis.

A resolução de Q2, Q3 e Q4 está relacionada a atribuir algum significado a fatos específicos. No caso, compreensão do sistema de numeração decimal (lembrar o significado dos termos unidade e dezena e utilizá-los na interpretação na situação proposta), compreensão do conceito de grandezas proporcionais (lembrar o significado da expressão "grandeza proporcional" e utilizá-lo para concluir algo a respeito da situação apresentada) e compreensão do conceito de potência com base negativa.

As questões Q7 e Q8 foram classificadas na dimensão de processo cognitivo aplicar, associadas com um tipo de conhecimento procedimental. Para resolvê-las, é necessário executar algum tipo de procedimento numa situação particular; no caso de Q7 é necessário calcular a taxa mensal de juros sendo conhecidos o capital inicial, o montante e o tempo. Para isso, o estudante necessita recordar alguma forma de relacionar essas grandezas (como, por exemplo, a fórmula $M=C_{0}(1+t)$, ou o raciocínio subjacente à sua dedução), compreendê-la e utilizá-la a partir dos dados específicos para essa situação. Já para resolver Q8, é necessário recordar e

\footnotetext{
${ }^{4}$ Tal situação foi evidenciada em um dos encontros de formação continuada, na qual um dos professores participantes disse "não admitir" que seus estudantes utilizassem o termo "menos 6", uma vez que o correto seria "negativo 6", sob a alegação de que esse estudante seria incapaz de lidar com números negativos se ele "nem mesmo" sabe o "jeito certo de falar".
} 
compreender algum procedimento para o cálculo da área de um triângulo sendo conhecidas as coordenadas dos seus vértices, e aplicá-lo a partir dos dados conhecidos.

As questões classificadas como Q7 e Q8 são as que mais estão presentes nas provas analisadas. Em geral, relacionam-se à aplicação de algum método, algoritmo ou técnica em situações idênticas ou similares às anteriormente apresentadas pelo professor em sala de aula. Embora seja importante que estejam presentes em provas escritas, quando propostas de forma excessiva contribuem para reforçar uma ideia de Matemática enquanto "aplicação de técnicas", o que vai de encontro aos princípios difundidos pela Educação Matemática. No caso do material analisado, a presença dessas questões era bastante evidente nas provas do $8^{\circ}$ e $9^{\circ}$ anos do Ensino Fundamental e no $3^{\circ}$ ano do Ensino Médio. Quatro das cinco provas do $3^{\circ}$ ano do Ensino Médio analisadas continham apenas questões desse tipo.

As questões Q9 e Q10 ilustram a categoria avaliar, e os domínios conceitual e procedimental do conhecimento. Para resolvê-las, o estudante é convidado a fazer algum tipo de julgamento ou emitir algum tipo de parecer, com base nas evidências apresentadas. Outra questão presente no material analisado, classificada do mesmo modo que Q10, foi a seguinte: "Em sua opinião, é vantajoso utilizar regras [de operações] das potências? Justifique. Dê exemplos". Embora nesse tipo de questão o estudante seja convidado a argumentar com base no conhecimento de certos procedimentos (operar com potências), cabe salientar que o uso do comando "em sua opinião" possibilita apresentar tanto a resposta sim quanto a resposta não, e ambas devem ser consideradas corretas, desde que justificadas e acompanhadas de exemplos que ilustrem essa opinião. Caso seja objetivo do professor que o estudante responda "sim", a questão deveria ser apresentada de outro modo, como por exemplo: "Em nossas aulas, vimos que a utilização de propriedades ao efetuar operações com potência pode ser vantajosa. Apresente um argumento para justificar essa vantagem e construa um exemplo ilustrando”.

No material analisado, não foram identificadas questões classificadas segundo as categorias analisar e criar, nem mesmo remetendo a subcategoria de conhecimento do tipo metacognitivo.

\section{Considerações finais}

Tomando por base a Taxionomia revisada de Bloom, este artigo apresentou uma análise de itens de questões de provas escritas de Matemática elaboradas por professores do Ensino Fundamental II e Ensino Médio de escolas públicas. Como apontado por Bloom et al. (1983), uma das principais dificuldades na categorização de itens ou questões, como a que nos propusemos fazer, diz respeito à necessidade de se conhecer o contexto em que as provas foram aplicadas e também as experiências educacionais anteriores dos estudantes que resolveram as provas. Tal dificuldade foi minimizada por conta das informações obtidas nos encontros de formação continuada com os professores que elaboraram as provas. Ainda assim, para a realização da classificação foram assumidas hipóteses acerca de conhecimentos da qual os estudantes disporiam quando da resolução dessas questões.

A análise realizada apontou uma prevalência massiva de itens classificados nos níveis mais baixos do domínio cognitivo (lembrar, entender e aplicar) e uma quase ausência de itens 
nos níveis mais elaborados (analisar, avaliar e criar). Uma das razões que justifica essa prevalência é a ideia arraigada no ambiente escolar de Matemática enquanto aplicação de técnicas e procedimentos, e que, portanto, o estudante precisa ser "treinado", ideia essa muitas vezes reforçada por avaliações de larga escala aplicadas aos mais diferentes níveis de ensino; a valorização em sala de aula de uma avaliação classificatória, em detrimento a uma prática formativa; os tipos de itens presentes nas tarefas apresentados pela maioria dos livros didáticos presentes na escola; a ausência de políticas públicas e ações de formação continuada que professores que possibilitem reverter esse quadro.

Tais resultados corroboram a necessidade de estudos e propostas de formação continuada que oportunizem ao professor repensar: (i) os instrumentos avaliativos que utiliza (em geral, prioritariamente a prova escrita), (ii) a elaboração das tarefas que propõe (em geral, restritas aos modelos presentes em livros didáticos) e, (iii) a sua própria prática avaliativa.

Nesse sentido, uma das ações propostas nas oficinas consistiu na reelaboração de itens tanto para compor provas escritas de Matemática, quanto para as próprias aulas. Assim, por exemplo, ao invés de pedir que o estudante apenas determine as raízes de uma equação do $2^{\circ}$ grau (situação essa bastante recorrente nas provas analisadas), o professor pode propor que o estudante avalie se a fórmula de Bháskara é o procedimento mais adequado para resolver qualquer tipo de equação do $2^{\circ}$ grau. Uma questão desse tipo mobilizaria a ação de avaliar (dimensão de processo cognitivo), pautada um conhecimento do tipo metacognitivo (no sentido de escolher o melhor método), uma vez que o estudante poderia sugerir que equações incompletas podem ser resolvidas, por exemplo, utilizando-se técnicas de fatoração.

Outra situação poderia demandar do estudante criar (dimensão do processo cognitivo) exemplos de equações do $2^{\circ}$ grau que apresentem uma única raiz real, ou não apresentem raízes reais, podendo para isso apoiar em conhecimentos sobre técnicas de resolução desse tipo de equação (conhecimento procedimental). Fazendo uso de um software gráfico, como por exemplo, o Geogebra, o professor pode propor ao estudante analisar a interferência do parâmetro $a$ no gráfico de uma função do $2^{\circ}$ grau $\left(y=a x^{2}+b x+c\right)$, mobilizando assim conhecimentos factuais e conceituais.

Discussões como essa oportunizam ao professor repensar, além das questões que propõe a seus estudantes e dos instrumentos que utiliza para avaliá-los (que não podem ficar restritos às provas escritas a serem resolvidas em espaços de tempo limitado), sua própria concepção de Matemática, bem como as atitudes e ações em sala de aula. Investigar potencialidades desse tipo de ação como oportunidade para o desenvolvimento profissional de professores de Matemática é uma das ações futuras do projeto da qual este artigo é recorte. Em especial, pretende-se analisar como professores (re)significam temáticas que trabalham na Educação Básica a partir de análises das questões que propõe a seus estudantes num contexto de avaliação.

Bloom et al. (1983, p. 19) apontam que, para que seja considerada um instrumento adequado e eficaz, a taxionomia "deverá ser um fonte de estímulos para a reflexão sobre os problemas educacionais”, bem como proporcionar aos especialistas em avaliação e professores "uma base de orientações quanto a métodos de desenvolvimento curricular, técnicas de ensino e técnicas de avaliação". Espera-se que, pelo menos em algum grau, esse artigo tenha contribuído nesse sentido. 
Trevisan, A. L.; Amaral, R. G.

\section{Agradecimentos}

Agradecemos o apoio financeiro recebido da Fundação Araucária (Convênio 386/2012), bem como a disponibilidade dos professores participantes da pesquisa.

\section{Referências}

ANDERSON, L. W.; KRATHWOHL, K. R. A. Taxonomy for learning, teaching and assessing: a revision of Bloom's taxonomy or educational objectives. New York: Longman, 2001.

ANTUNES, C. A avaliação da aprendizagem escolar. 4. ed. Petrópolis: Vozes, 2012.

BARBOZA, W. L.; TREVISAN, A. L.; AMARAL, R. G. Oficina de avaliação: a difícil tarefa de avaliar com qualidade. In: SEMINÁRIO NACIONAL DE ENSINO DE CIÊNCIAS E TECNOLOGIA, 3., 2012, Ponta Grossa. Anais... Ponta Grossa: UTFPR, 2012. Disponível em: <http://www.sinect.com.br/2012/selecionados.php>. Acesso em: 25 ago. 2012.

BLOOM, B. et al. Taxonomia dos objetivos educacionais: domínio cognitivo. Porto Alegre: Globo, 1983.

BOGDAN, R. C.; BIKLEN, S. K. Investigação qualitativa em educação. Porto: Porto Editora, 1994.

BURIASCO, R. L. C.; FERREIRA, P. E. A.; CIANI, A. B. Avaliação como prática de investigação (alguns apontamentos). BOLEMA: boletim de educação matemática, Rio Claro, v. 22, n. 33, p. 69-96, 2009. Disponível em: <http://www2.rc.unesp.br/ bolema/?q=node/227>. Acesso em: 16 mar. 2016.

FERRAZ, A. P. C. M.; BELHOT, R. V. Taxonomia de Bloom: revisão teórica e apresentação das adequações do instrumento para definição de objetivos instrucionais. Gestão \& Produção, São Carlos, v. 17, n. 2, p. 421-431, 2010. Disponível em: <http://dx.doi. org/10.1590/S0104-530X2010000200015>. Acesso em: 16 mar. 2016.

LUCKESI, C. C. Avaliação da aprendizagem escolar. 13. ed. São Paulo: Cortez, 2002.

. Avaliação da aprendizagem na escola: reelaborando conceitos e recriando a prática. 2. ed. Salvador: Malabares Comunicação e Eventos, 2005.

MORETTO, V. P. Prova: um momento privilegiado de estudos, não um acerto de contas. Rio de Janeiro: Lamparina, 2010.

Artigo recebido em 01/04/2015. Aceito em 24/10/2015.

Endereço para contato: Avenida Brasília, 2051, Bairro Alto da Boa

Vista, CEP 86600-224, Rolândia, PR, Brasil. 